\title{
Coffin-Siris Syndrome in Two Sisters in Nepal
}

\author{
Ojha $A R^{1}$, Fong $\mathrm{CT}^{2}$, Pandey $\mathrm{AS}^{3}$
}

${ }^{1}$ Dr. Anil Ojha, MBBS, MD, Assistant Professor, Department of Paediatrics, Kathmandu Medical College and Teaching Hospital, Sinamangal, Kathmandu, Nepal, ${ }^{2}$ Dr. Chin-To Fong, Associate Professor and Chief, Division of Paediatric Genetics, Department of Paediatrics, University of Rochester School of Medicine and Dentistry, Rochester, NY, USA, ${ }^{3} \mathrm{Dr}$. Arti Sharma Pandey Ph.D., Associate Professor and Head, Department of Biochemistry, Kathmandu Medical College, Basic Sciences Block, Duwakot, Bhaktapur, Nepal.

\section{Introduction}

$\mathrm{C}^{\mathrm{a}}$ offin-Siris syndrome (CSS) has been described as mental retardation associated with coarse facial features, hypertrichosis and hypoplastic or absent fingernails or toenails (OMIM 135900). Coffin and Siris were the first to describe three unrelated female children with severe mental and developmental retardation, sparse scalp hair, and coarse appearing facies with bushy eyebrows, a wide mouth, and thick lips ${ }^{1}$. A characteristic feature was brachydactyly of the fifth digits of both hands and feet with absence of nails of terminal phalanges.

CSS is generally assumed to be inherited in an autosomal recessive manner, although autosomal dominant inheritance has not been formally excluded ${ }^{2,3}$. In 2001, Fleck et. al. proposed the minimal criteria for diagnosis of CSS which include some degree of developmental delay, coarse facial appearance, hirsutism, hypoplastic or absent fifth fingernails or toenails, and hypoplastic or absent fifth distal phalanges ${ }^{4}$. Recently, Schrier et al defined a "classic" and "variant" type of CSS to develop an algorithm to determine the likelihood of diagnosis of $\mathrm{CSS}^{5}$.

The only documented case of Coffin Siris syndrome in South Asia is that of a nine year old girl in India who also had the Mayer-Rokitansky-Kuster-Hauser syndrome ${ }^{6}$. No other cases have been reported from the rest of the South Asian countries and the incidence of CSS in this region is unknown. We report here the case

\begin{abstract}
Coffin-Siris syndrome (CSS) has the characteristic feature of brachydactyly of the fifth digit of hands and feet accompanying cognitive and developmental delay. There is an overlap of symptoms with other conditions making the diagnosis of CSS difficult. An algorithm to look for a set of characters was followed for diagnosis of CSS in two sisters in Nepal. This is the first case of CSS reported from this country.
\end{abstract}

of CSS in two sisters in Nepal diagnosed with CSS on the basis of the algorithm developed by Schrier et $\mathrm{al}^{5}$.

\section{The Case}

Two sisters were identified as having CSS at an Institute for mentally retarded children during a consultation visit to the center. After informing the parents, the family was called to Kathmandu Medical College, Department of Paediatrics, for a clinical examination. A thorough family history was taken. Both sisters were examined by an otorhinologist and advised for otoacoustic emission (OAE) test. Ophthalmic evaluation was also done.

The sisters were 11 and 8.5 years of age, born of non-consanguineous parents in the remote district of far western Nepal. Both girls were delivered at home and were reportedly small at birth. Dentition was delayed (1.5 years) and later, both showed marked cognitive and developmental delay and failure to thrive. Both girls showed intolerance for mother's milk since birth. The problem resolved by the time the girls were one year of age, but both continue to have frequent diarrheal episodes as well as infections. There was no history of seizures or heart disease. There is reportedly no history of a similar condition in either parent's side of family.

There was a family history of a growth on the back in girls' father, his younger brother and a younger sister, which suppurated and resulted in temporary paraplegia in all affected, and death of the sister at 9 years of age.

\section{Address for correspondence \\ Dr. Arti Sharma Pandey \\ E-mail: rtpandey@yahoo.com}

\section{How to cite this article ?}

Ojha AR, Fong CT, Pandey AS. Coffin-Siris Syndrome in Two Sisters in Nepal. J Nepal Paediatr Soc 2013;33(2):132-135. 
The mother's first born was unable to suckle and died at 15 days of age. The sisters have a younger brother who is unaffected.

General examination of the girls showed their height, weight and head circumference to be below the third percentile for age. They were proportionately short in stature. Both had marked cognitive and developmental delay. HEENT examination showed both sisters to have a high palate, a low hairline, sparse scalp hair and long eyelashes. Both had hypoplastic fifth phalanx which was confirmed by X-rays (Figure 1). Both also had dysplastic nails of fifth digits in the upper limbs. The younger sibling had coarse facies, a depressed nasal bridge, bushy eyebrows and thick vermilion, and was hyperactive. The older sister had a thick vermilion, anteverted nares, thin eyebrows and upslanting of eyes. The examination of precordium and abdomen was not contributory. OAE and ophthalmic evaluations were normal.

\section{Discussion}

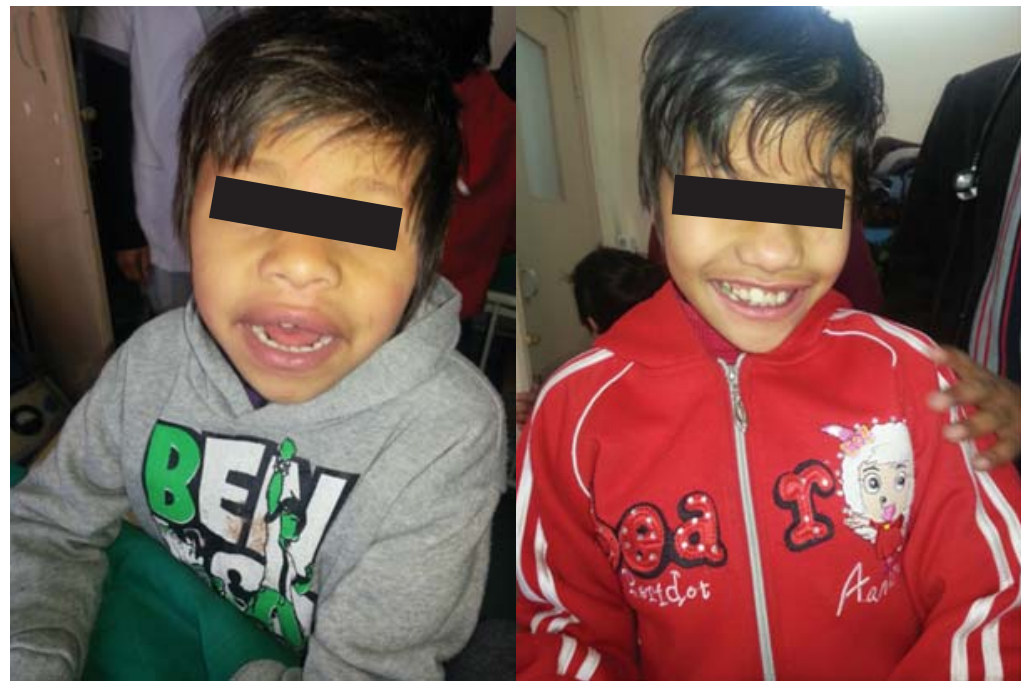

Fig 1: Younger (left) and older (right) sisters with coarse facial features

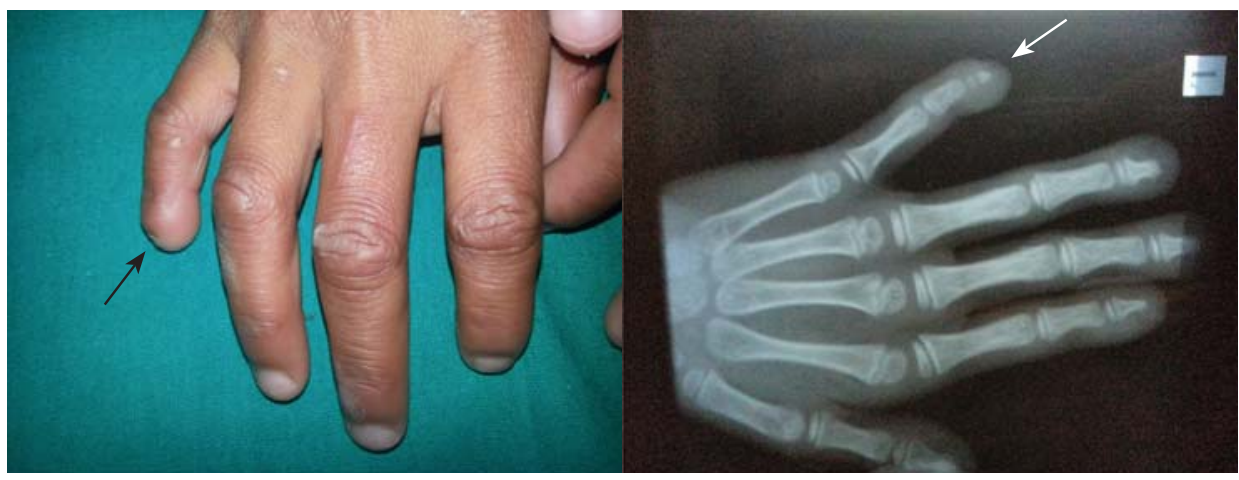

Fig 2: Younger sister showing hypoplastic finger nail and hypoplastic distal phalynx

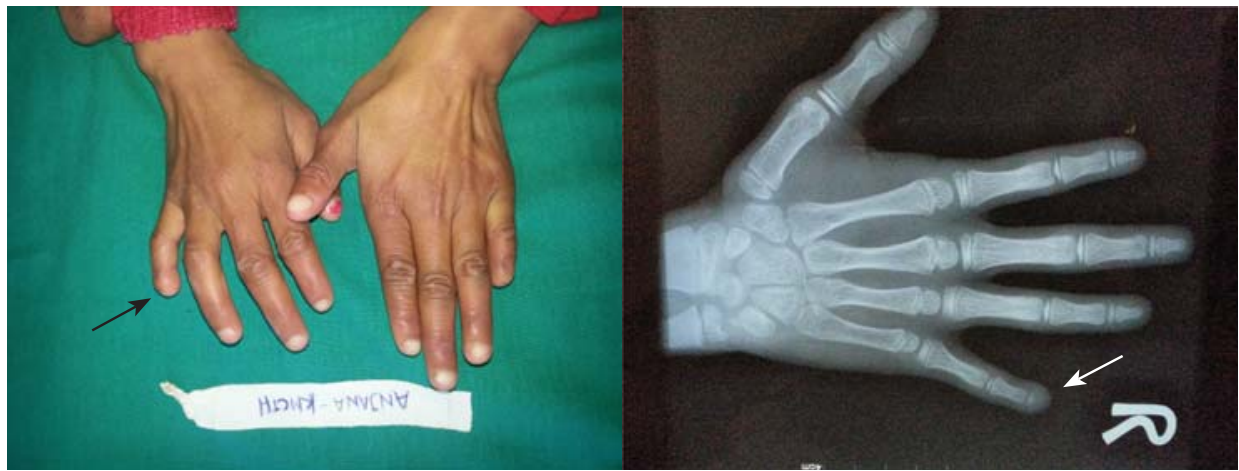

Fig 3: Older sister showing hypoplastic finger nail and hypoplastic distal phalynx 
DD, CD with fifth digit (Yes) $\longrightarrow$

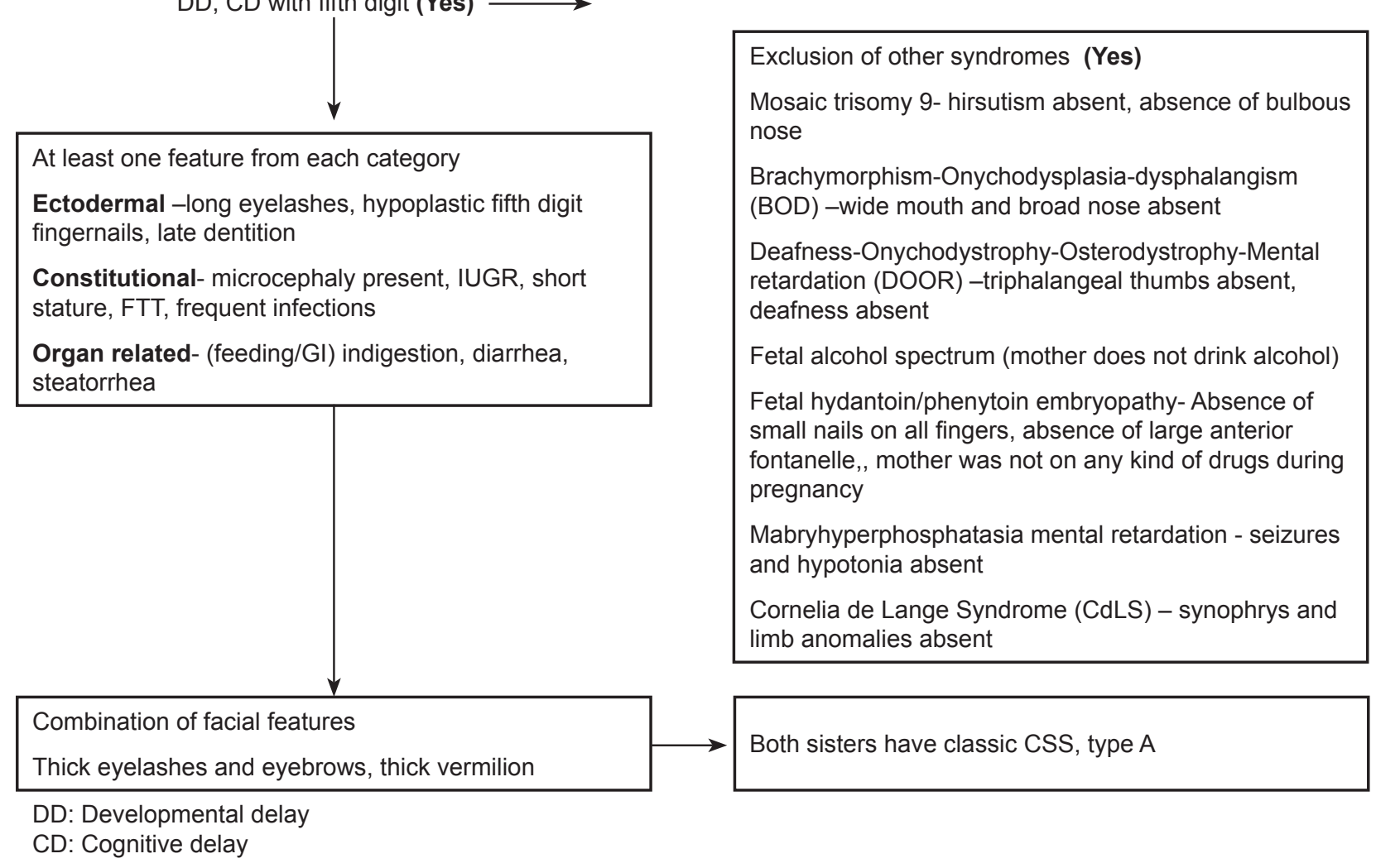

Table 1: Criteria for diagnosis of CSS according to the algorithm by Schrier et al. ${ }^{5}$

The algorithm developed by Schrier et al was followed to confirm the diagnosis and determine the class of CSS, as shown in Table 1.

Both sisters fit the criteria for classic CSS, type A. Several translocations have been reported in individuals with CSS, and in particular, translocations involving 7q32$7 q 34$ have been postulated as a candidate region ${ }^{8,9}$. Recently, the genes coding for the various subunits of the SWI/SNF complex, SMARCB1, SMARCA4, SMARCA2, SMARCE1, ARID1A and ARID1B, were found to be mutated in individuals clinically suspected of having CSS. ${ }^{10}$ These studies also confirmed the inheritance to be autosomal dominant. Since in the presented case, one daughter is deceased, and two are affected, with the only male child unaffected, it is likely that the father is the carrier of the mutation. A molecular investigation of the mutations of the SWI/SNF complex in the two sisters will follow, to relate the sisters' phenotype to a genotype.

\section{Conclusion}

Coffin Syris syndrome is a rare form of congenital disorder inherited in autosomal recessive fashion presenting with mental retardation, coarse facial features, hypertrichosis and hypoplastic or absent fingernails or toenails. A clinical diagnosis of this condition requires at least one feature from three categories namely ectodermal, constitutional and organ related. It is important in our setting as we lack facilities for genetic studies.

\section{References}

1. Coffin GS, Siris S. Mental retardation with absent fifth fingernail and terminal phalanx. Am J Dis Child 1970;119:433-39.

2. Carey JC and Hall, BD. The Coffin-Siris Syndrome: five cases including two siblings. Am J Dis Child 1978;132:667-71.

3. Haspeslagh M, Fryns JP and van den Berghe $\mathrm{H}$. Report of a family and further delineation. Clin Genet 1984;26:374-78.

4. Fleck BJ, Pandya A, Vanner L, Kerkering K, Bodurtha J. Coffin-Siris Syndrome: Review and presentation of new cases from a questionnaire study. Am J Med Genet 2001;99:1-7.

5. Schrier SA, Bodurtha JN, Burton B, Chudley AE, Chiong MD, D'avanzo MG, Lynch SA, Musio A, Nyazov DM, Sanchez-Lara PA, Shalev SA, Deardorff MA The Coffin-Siris Syndrome: A proposed diagnostic approach and assessment of 15 overlapping cases. Am J Med Genet 2012; Part A 158A:1865-1876. 
6. Goyal D, Yadav DK, Shukla U, SethiSK. CoffinSiris syndrome with Mayer-Rokitansky-KusterHauser syndrome: a case report. J Med Case Rep 2010;4:354.

7. McPherson EW, Laneri G, Clemens MM, Kochmar SJ, Surti U. Apparently balanced t(1:7)(q21.3;q34) in an infant with Coffin-Siris Syndrome. Am J Med Genet 1997;71:430-433.

8. McGhee EM, Klump CJ, Bitts SM, Cotter PD, Lammer EJ. Candidate region for Coffin-
Siris syndrome at 7q32-34. Am J Med Genet 1991;41:350-354.

9. TsurusakiY, Okamoto N, Ohashi H, Kosho T, Imai Y, Hibi-Ko Y. et al. Mutations affecting components of the SWI/SNF complex cause Coffin-Siris syndrome. Nature Genetics 2012;44(4):376-378.

10. Santen GWE, Emmelien A, Sun Y, Almomani R, Gilissen C, Nielsen M, et al. Mutations in the SWI/ SNF chromatin remodeling complex gene ARID1B cause Coffin-Siris syndrome Nature Genetics 2012;44(4):379-380. 